\title{
A MODIFICATION OF ROEMER'S INTRACUTANEOUS METHOD FOR THE DETERMINATION OF SMALL AMOUNTS OF DIPHTHERIA ANTITOXIN IN BLOOD SERA*
}

Abraham Zingher

From the Research Laboratory of the Department of Health, New York City

A convenient, practical, and economical test for the determination of the diphtheria-antitoxin content of blood sera is important for a number of reasons, among which may be mentioned the desirability of estimating quantitatively the efficiency of active immunization with toxin-antitoxin, the development of an active immunity after an attack of diphtheria, the antitoxin content of the blood at varying intervals after a single therapeutic or prophylactic injection of diphtheria antitoxin, the effect of one injection of antitoxin on the duration of immunity conferred by a second injection, etc. Such determination of the antitoxin content would help to give us a solid scientific foundation in many experimental and clinical problems connected with the subject of diphtheria.

The older subcutaneous test of Ehrlich for determining the antitoxin content by the death of the guinea-pig has been universally accepted as a standard, but it cannot be used with any degree of accuracy when less than $1 / 20$ of a unit of antitoxin to the cubic centimeter of serum is to be determined. The subcutaneous test requires a large amount of serum for each test, especially when the test is made for a fraction of a unit of antitoxin. This amount is not always obtainable in the case of human beings, especially when we are dealing with small children. In addition, the subcutaneous test is expensive in that it requires the use of one guinea-pig for each test. A method, therefore, that wotld enable us accurately to determine as little as $1 / 200$ unit of antitoxin, require but a small amount of serum, and be saving of animals, would be of considerable advantage. When a larger series of sera is to be tested for small amounts of antitoxin, the intradermal method is practically the only feasible one.

Recent work in active immunization against diphtheria ${ }^{1}$ has shown successful results in producing an antitoxic immunity in $90-95 \%$ of

* Received for publication May 7, 1916.

1 Park and Zingher: Jour. Am. Mer. Assn,, 1915, 65, p. 2216. Am. Jour. Pul. Health, 1916,6 , p. 431 . 
susceptible individuals. This was shown by negative Schick reactions in individuals who had previously given positive reactions. The negative Schick reaction, however, indicates only that the individual has become immune by the development of $1 / 30$ of a unit (according to our work 1/100 unit) or more of antitoxin to the cubic centimeter; it does not show the exact amount of antitoxin that has been produced. Altho clinically it is possible to demonstrate the continuation of the immunity by repeating the Schick test at definite intervals, yet for estimating the duration of immunity it is important, according to v. Behring, to establish quantitatively the amount of antitoxin produced in the actively immunized persons.

In 1909 Römer and Sames ${ }^{2}$ published a method for testing small amounts of antitoxin in blood sera. This test was based on a previous observation made by Römer ${ }^{8}$ that $1 / 500 \mathrm{M}$. L. D. of a toxin was still capable of producing a distinct local necrosis when injected intradermally into the guinea-pig.

Römer and Sames determined the necrosing dose of a toxin in the guinea-pig-for example, the amount of toxin added to one unit, or any fraction of a unit of antitoxin, which is still capable of producing a slight local necrosis. This was called the Ln dose of the toxin. They found that $1 / 500 \mathrm{M}$. L. D. of the toxin was sufficiently neutralized by $1 / 40,000$ unit of antitoxin to just produce a slight local effect in the animal. This amount of antitoxin in $1 / 20$ c.c. of undiluted serum (the quantity used in the test with an equal volume of toxin solution) represents 1/2000 unit of antitoxin to the cubic centimeter.

The method suggested by Römer and Sames and later applied by Römer and Somogyi ${ }^{4}$ to the testing of concentrated antitoxic horse sera, has worked satisfactorily in their own hands, but has not given reliable results in the hands of others who have tried it repeatedly. One of the difficulties lies in their attempt to make too fine a distinction between the various lesions of closely lying tests. They claim to be able to distinguish a 5\% difference in antitoxin content between the individual tests. After repeated trials this has seemed to me difficult and unnecessary, especially when we are dealing with an antitoxin content between $1 / 200$ unit and 10 units to the cubic centimeter of serum. A second difficulty and an equally unnecessary point is the long time, 24 hours, that the toxin and serum are required to stand before injection into the animal. Thirty minutes has proved to be a sufficient time to allow for the full union between toxin and antitoxin,

2 Ztschr. f. Immunitätsf., 1909, 3, p. 49.

3 Ibid., p. 208.

4 Ibid., p. 433. 
even in the dilutions used in the test. A third difficulty lies in the necessity of establishing a new toxin test dose, the Ln. These factors have undoubtedly discouraged the use of a test which is inherently valuable.

The modification which I have found simple and workable in the testing of many hundreds of human and animal sera, has the following advantages:

(1) The $\mathrm{L}+$ of the toxin is taken as the test dose and so diluted that each cubic centimeter represents $1 / 100 \mathrm{~L}+$ dose.

(2) Two test points are established with each serum, the test at which no lesion develops, and the one for twice the amount of antitoxin at which a distinct lesion appears. Within these two limits lies the antitoxin content of the serum. The first test indicates a balanced combination or a slight excess of antitoxin, while the second shows the presence of a trace of free toxin. The latter test which produces a slight local necrosis represents the antitoxin content of the serum. When the necrosis is more marked, an intermediate test is made. Example: Slight necrosis at 1 unit, no necrosis at $1 / 2$ unit. Antitoxin content 1 unit. If necrosis were marked, the test would be repeated for $3 / 4$ unit.

(3) It saves animals in that 4 tests can be made on each guineapig. It also saves time, for the tests can be interpreted in from 48 to 72 hours.

(4) As little as $1 / 200$ unit of antitoxin can be determined in a serum with a fair degree of accuracy. If a distinct lesion appears at this test point, the serum is considered as having no antitoxin.

Details of THE TEST

(1) A standard well-ripened toxin is used, so diluted with normal salt solution that 1 c.c. represents $1 / 100 \mathrm{~L}+$ dose. A fresh dilution is prepared for each set of tests. If, for example, the $L+$ is 0.5 c.c., then that amount is diluted with 99.5 c.c. of sterile salt solution. The quantity of toxin added in the test varies with the antitoxin content for which the test is made (see Table 1).

(2) The serum to be tested is used either undiluted or diluted 1:10 (0.2 c.c. serum +1.8 c.c. salt solution $), 1: 100(0.2$ c.c. of serum dilution $1: 10+$ 1.8 c.c. salt solution), etc. The amount of serum used in the test is always 0.2 c.c., except when the test is made for $1 / 200$ unit of antitoxin; then 0.4 c.c. of undiluted serum is added to 0.2 c.c. of toxin solution.

(3) Normal salt solution is added to balance the mixture. The amount is the same as that of the toxin solution minus $0.2 \mathrm{c.c}$., which represents the serum.

(4) After the addition of toxin, serum, and salt solution, the mixture is allowed to stand for 30 minutes at room temperature before it is injected into the guinea-pig. This time is utilized in preparing and tagging the guinea-pigs. 
(5) The guinea-pigs $(300-350 \mathrm{gm}$.) are prepared by removing the hair from the abdomen. This is best accomplished by simply pulling it out, a central line of hair being left to divide the abdominal surface into halves. The pulling of the hair is easily and rapidly carried out, and is probably less painful than the action of a depilatory like calcium hydrosulfid or shaving of the hair. The first occasionally leads to local eczema, the second to abrasions that interfere with the reading of the test.

(6) The animal holder is simply an elevated board with 4 openings for loops of cord with which to fasten the limbs of the animal. This simple device is essential in accurate work and facilitates the exact placing of the injections.

(7) A 1-c.c. "Record" or tuberculin syringe and a fine steel or platinumiridium needle are necessary.

(8) Four injections are made into each guinea-pig, the abdomen being for this purpose divided into right upper (R. U.), right lower (R. L.), left upper (L. U.), and left lower (L. L.) quadrants. The injections are made as far apart as possible to avoid a fusion of the lesions. Two-tenths cubic centimeter of each test mixture is injected intradermally. Care with each injection is essential if uniform results are to be obtained. A good guide in the insertion of the needle into the proper layer of the skin is to be able to see its oval opening through the superficial layers of the epidermis. If the fluid has been injected properly, a tense local sharply circumscribed swelling appears, which shows the prominent openings of the hair follicles.

(9) The places of injection on the guinea-pigs are examined at the end of $24,48,72$, and 96 hours, and a careful record is kept of each test (Table 3 ). The following changes in the local appearance of the skin at the sites of injection are noted:

(a) Redness, whether marked (R) or slight ( $r$ ).

(b) Induration, whether marked (Id), moderate (mod), or slight (sl).

(c) Necrosis, marked (N) or slight ( $\mathrm{n}$ ), or only superficial scaling (scal). The induration is most marked at the end of 48 or 72 hours; the necrosis appears at the end of 72 hours.

The following tables show (1) the amounts of toxin, serum, and salt solution used in the test; $(2)$ the method followed in the examination of several sera; (3) a sample page of the daily record of the tests on the guinea-pig; and (4) an experiment on 4 horses showing the development of antitoxin after injections of small amounts of diphtheria toxin-antitoxin.

TABLE 1

Intradermal Estimation of Diphtheria Antitoxin

\begin{tabular}{|c|c|c|c|c|c|c|c|c|c|}
\hline $\begin{array}{l}\text { Test Toxin } \\
1 \text { c.c. }=\frac{1}{100} \mathrm{~L}+\end{array}$ & $\begin{array}{c}\text { Normal } \\
\text { Salt } \\
\text { Solution }\end{array}$ & & Serum & \multirow{5}{*}{$=$} & Undiluted & $1: 10$ & $1: 100$ & $1: 1000$ & $1: 10,000$ \\
\hline 0.2 & 0.0 & + & 0.2 & & 0.01 unit & 0.1 unit & 1 unit & 10 units & 100 units \\
\hline 0.4 & 0.2 & + & 0.2 & & 0.02 unit & 0.2 unit & 2 units & 20 units & 200 units \\
\hline 1.0 & 0.8 & + & 0.2 & & 0.05 unit & 0.5 unit & 5 units & 50 unitg & 500 units \\
\hline 2.0 & 1.8 & + & 0.2 & & 0.10 unit & 1.0 unit & 10 units & 100 units & 1000 units \\
\hline $\begin{array}{l}\text { Fvery } 0.2 \text { c.c. } \\
\text { equal to... }\end{array}$ & of toxin & & $n$ ad & $\begin{array}{l}\text { is } \\
\ldots\end{array}$ & 0.01 unit & 0.1 unit & 1 unit & 10 units & 100 units \\
\hline
\end{tabular}


TABLE 2

Estrmation of Dipilueria Antitoxin by the Intradermal, Method

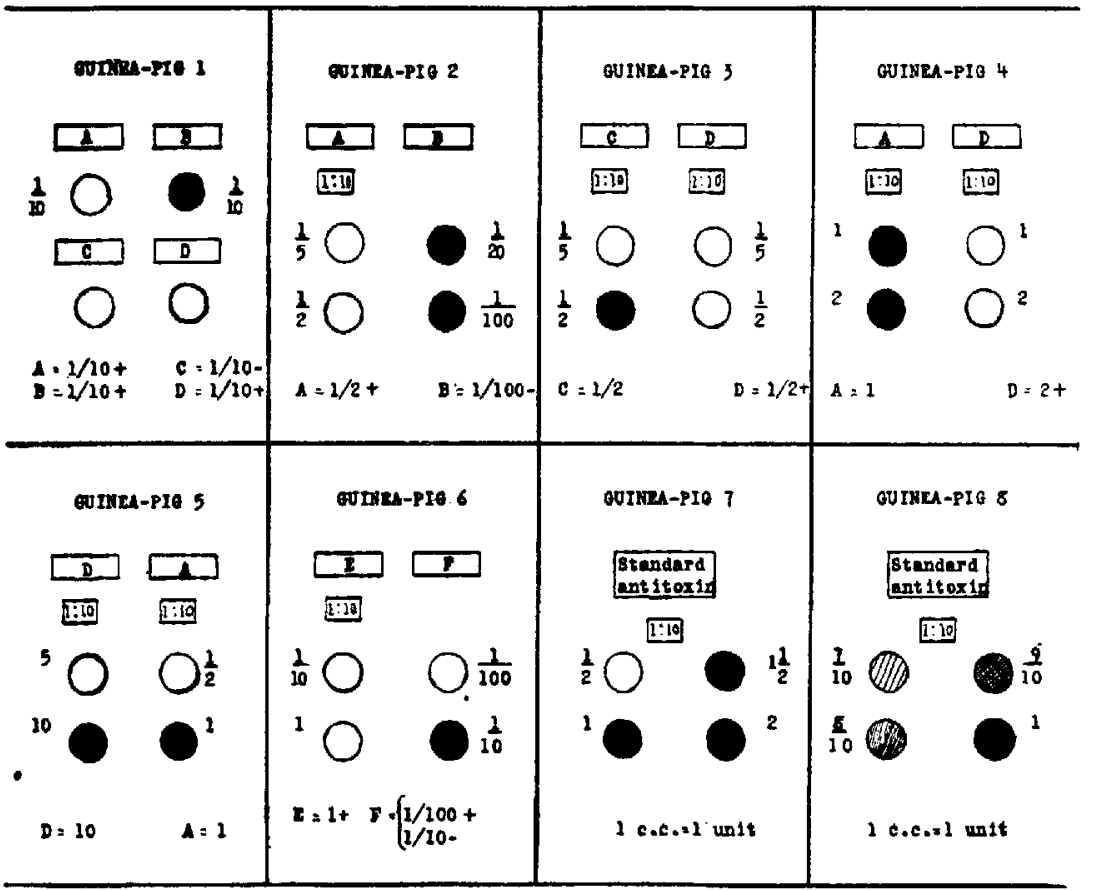

Rectangles indicate blood sera and their dilutions. Circles indicate results of tests, the white ones meaning no lesion, the black ones local necrosis, and the shided ones slight local inflammatory lesions.

TABLE 3

Sampte Page of Daily Record of Tests

\begin{tabular}{|c|c|c|c|c|c|c|c|c|}
\hline \multirow{2}{*}{ Sera } & \multirow{2}{*}{$\begin{array}{c}\text { Guinea- } \\
\text { pig }\end{array}$} & \multirow{2}{*}{$\begin{array}{c}\text { Place } \\
\text { of } \\
\text { Injection }\end{array}$} & \multirow{2}{*}{$\begin{array}{l}\text { Amount of } \\
\text { Antitoxin } \\
\text { Tested }\end{array}$} & \multicolumn{4}{|c|}{ Daily Observations } & \multirow{2}{*}{$\begin{array}{c}\text { Result } \\
\text { of } \\
\text { Tests }\end{array}$} \\
\hline & & & & Feb. 13 & Feb. 14 & Feb. 15 & Feb. 16 & \\
\hline$A$ & 1 & $\mathbf{R} \mathrm{U}$ & $1 / 10$ unit & $\mathrm{OK}$ & $\mathrm{OK}$ & $O K$ & $\mathrm{OK}$ & $1 / 10+$ \\
\hline $\mathrm{B}$ & 1 & B L & $1 / 10$ unit & $\mathrm{Sl}$ & $\underset{\mathrm{R}}{\operatorname{Mod}}$ & $\stackrel{\mathrm{Id} n}{\mathrm{R}}$ & $\underset{\mathrm{R}}{\operatorname{Id} \mathrm{N}}$ & $1 / 10-$ \\
\hline $\mathrm{O}$ & 1 & I. $\mathrm{U}$ & $1 / 10$ unit & OK & $O K$ & $\overline{O K}$ & $\mathrm{OK}$ & $1 / 10+$ \\
\hline $\mathrm{C}$ & 1 & $L \mathbf{L}$ & 1/5 unit & $\begin{array}{l}\text { Sl } \\
\mathbf{r}\end{array}$ & $\underset{\mathrm{R}}{\operatorname{Mod}}$ & $\underset{R}{\operatorname{Mod}} n$ & $\underset{\mathbf{R}}{\operatorname{Mod} n}$ & $1 / 5$ \\
\hline
\end{tabular}

RU, RL, L U, LI refer to the right upper, right lower, left upper, and left lower quadrants, respectively, of the guinea-pig abdomen.

$\mathrm{OK}=$ no reaction; $\mathrm{Sl}=$ slight induration; Mod $=$ moderate induration: $\mathrm{Id}=$ marked induration. $\mathbf{N}=$ marked necrosis; $\mathrm{n}=$ slight necrosis. $\mathrm{k}=$ marked redness; $\mathrm{r}=$ slight redness. 


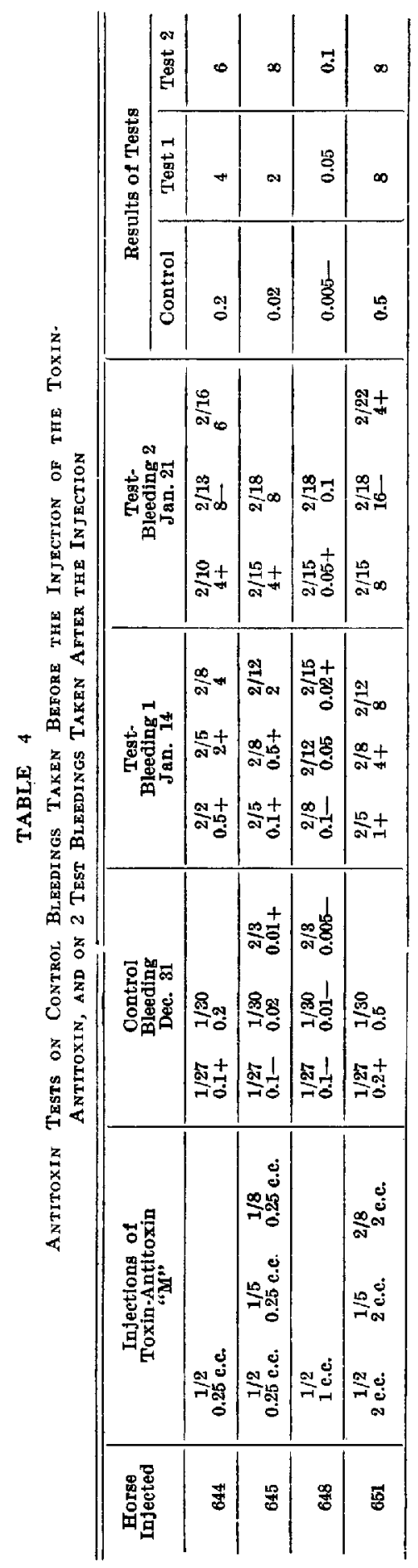


Guinea-pig 1 (Table 2) shows the preliminary results of tests on 4 different sera for $1 / 10$ unit of antitoxin. Sera A, C, and D completely neutralized the toxin solution and no lesions appeared. Serum $B$ gave a necrosis. Result: $A, C$, and $D$ had more than $1 / 10$ unit, $B$ less than $1 / 10$ unit of antitoxin to the cubic centimeter.

Guinea-pigs 2 and 3 represent the 2 nd set of tests on the 4 sera. Serum A showed no lesion with the $1 / 2$-unit test, therefore more than $1 / 2$ unit was present. Serum B showed less than $1 / 100$ unit, a necrosis appearing with this test. The serum can be further tested for $1 / 200$ unit and if a definite lesion appears the serum is considered as having no antitoxin. Serum $C$ showed no lesion with $1 / 5$ unit, but a slight lesion with $1 / 2$ unit. Antitoxin content therefore was $1 / 2$ unit to the cubic centimeter. If a marked lesion had developed, an intermediate test for $1 / 3$ unit could be made. Serum $D$ had more than $1 / 2$ unit.

Guinea-pig 4 represents the 3 rd set of tests for Sera A and D. Serum $A$ showed a lesion with tests for 1 and 2 units. The antitoxin content was therefore 1 unit, since the test in Guinea-pig 2 with Serum A for $1 / 2$ unit showed no lesion. Serum D showed more than 2 units.

Guinea-pig 5 represents the 4th set of tests for Serum D. A lesion appeared with the test for 10 units and no lesion with the one for 5 units. The antitoxin content therefore equaled 10 units. Serum A was retested for $1 / 2$ and 1 unit to show the nonnecrosing and necrosing test points on the same animal.

By using 5 animals we were able to make 20 different tests, and arrive accurately at the antitoxin content of 4 different sera.

Guinea-pig 6 shows 2 sera, $E$ and $F$, on which the tests were made for widely separated antitoxin contents. This can be done when we wish to arrive rapidly at rough limits of the amount of antitoxin in a serum. Serum $E$ showed more than 1 unit, Serum $F$ more than $1 / 100$, but less than $1 / 10$ unit. Serum $E$ would have to be tested further for 10,100 units, etc., while Serum $F$ should be tested for $1 / 20$ and $1 / 50$ unit, if we wish to establish the accurate amount of antitoxin.

Guinea-pig 7 shows tests made by this method on the standard antitoxin furnished from the Hygienic Laboratory in Washington. Each cubic centimeter represents exactly one unit of antitoxin. With the intradermal test the antitoxin content was also definitely established as 1 unit to the cubic centimeter, no lesion appeared with the test for $1 / 2$ unit, but a distinct lesion with slight necrosis with the test for 
1 unit. The tests for $11 / 2$ and for 2 units showed more marked necrosing lesions.

Guinea-pig 8 shows the same standard antitoxin tested for $0.7,0.8$, 0.9 , and 1 unit. Slight inflammatory lesions were noticed even with the test for 0.7 unit. It is therefore best not to attempt to make too fine a differentiation between the slight lesions of closely lying tests, but to endeavor to obtain the necrosing and nonnecrosing points of a serum, the first representing twice the amount of antitoxin tested for in the second. When we are dealing with concentrated antitoxic sera (100-1000 units to the cubic centimeter) the intradermal test can give us only a preliminary idea of the antitoxin content; the more accurate estimation is subsequently made by the subcutaneous test.

\section{CONCLUSIONS}

An intradermal test is presented for estimating in an economical way small amounts of antitoxin.

The method is easily carried out, tho it requires for accuracy a uniform technic in making the dilutions of toxin and serums, the allowance of a uniform time period for the two to combine, uniformity in the method of injection into the guinea-pig, daily observations of the animals, and uniform interpretation of the tests.

Problems in experimental work in diphtheria and the accurate serologic control of actively immunized individuals can be carried out by this test. 